\title{
Achat pour médecins et cabinets médicaux
}

\section{(28) 89}
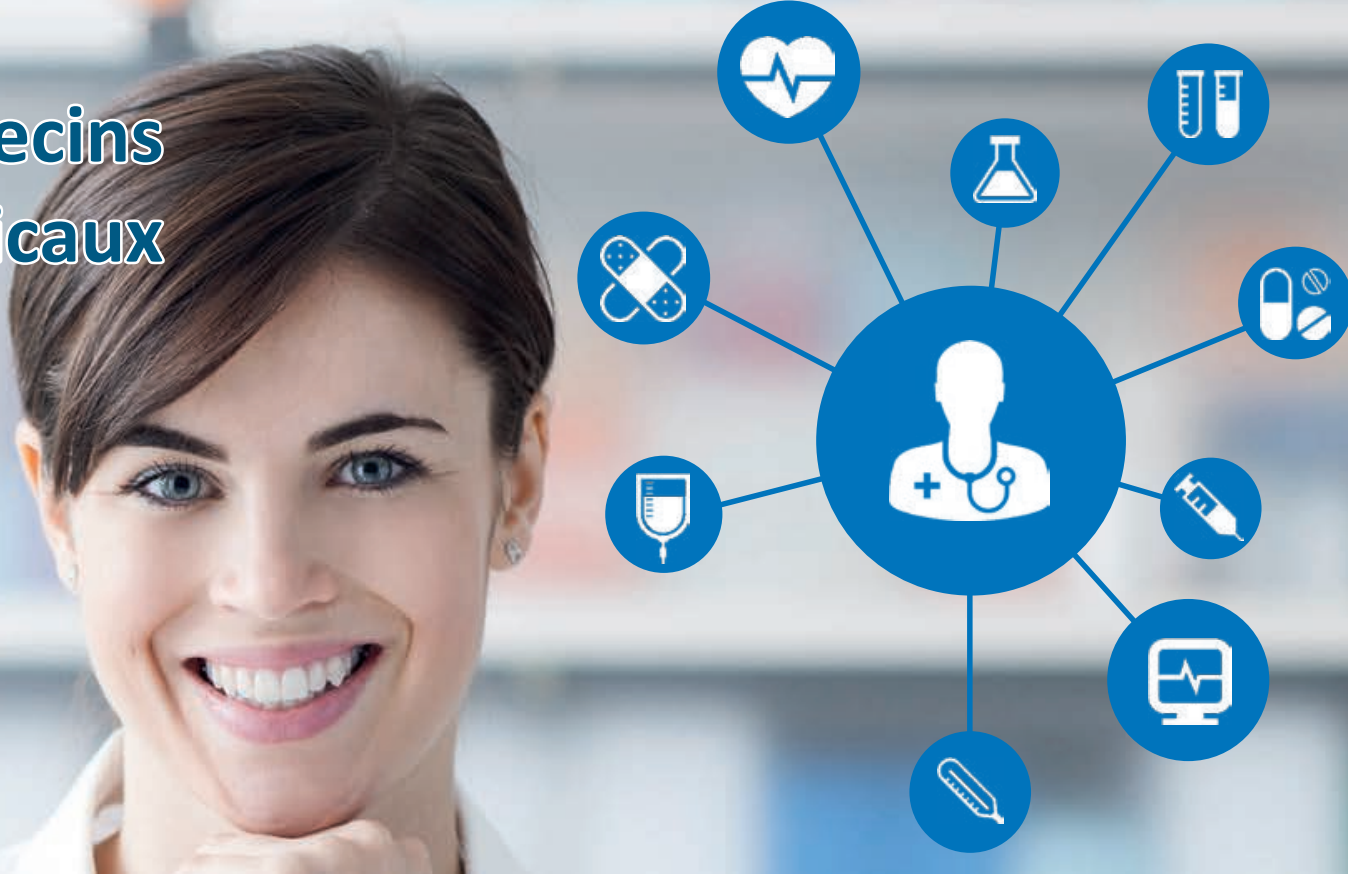

Economisez du temps et de l'argent grâce au service «Achat» de FMH Services:

- Jusqu'à $25 \%$ de rabais comme conditions spéciales auprès de nos fournisseurs partenaires

- Délais de paiement prolongés

- Traitement facile grâce à la facture collective mensuelle

- Commande directe auprès d'une large sélection de fournisseurs contractuels

Nos fournisseurs contractuels:

$\triangle \triangle$

aichelemedico

$\longrightarrow$

Finn Technologies oneprovideag

A MEMBER OF SYNLAB /

\section{smedico}

\section{ACHAT POUR MÉDECINS ET CABINETS MÉDICAUX}

Möbel mit System

\section{IFMHSERVICES}

$\square \quad$ Je suis intéressé par le service «Achat».

Veuillez me contacter.

Prénom / nom

Adresse

NPA / lieu

Téléphone privé / prof.

Atteignable de préférence vers

Adresse e-mail

Published under the copyright license "Attribution - Non-Commercial - NoDerivatives 4.0". No commercial reuse without permission.

\section{CONSULTING}

\section{FMH Consulting Services AG}

Avenue d'Ouchy 66, 1006 Lausanne

Tél. 0219224435

mail@fmhconsulting.ch - www.fmhservices.ch 